\title{
Twins’ Early Development Study (TEDS): A Multivariate, Longitudinal Genetic Investigation of Language, Cognition and Behavior Problems from Childhood Through Adolescence
}

\author{
Bonamy R. Oliver and Robert Plomin \\ Social, Genetic and Developmental Psychiatry Centre, Institute of Psychiatry, King's College London, United Kingdom
}

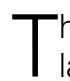
he Twins' Early Development Study (TEDS) is a large-scale longitudinal study of twins from early childhood through adolescence. Since its conception, TEDS has had as its focus the study of problematic development within the context of normal variation, mainly in the development of language, cognitive and academic abilities and behavior problems from multivariate quantitative and molecular genetic perspectives. TEDS twins have been assessed at 2, 3, 4, 7, 9, 10 and (currently) 12 years of age, and DNA collected from more than 12,000 children. Identified from birth records of twins born in the United Kingdom between 1994 and 1996, more than 15,000 pairs of twins originally enrolled in TEDS, and well over 13,000 pairs - representative of the UK population - remain involved in the study to date. Similar to many other twin and adoption studies, TEDS data indicate that both genetic and environmental influences are important in nearly all areas of behavioral development. Multivariate genetic analyses allow researchers to go beyond this basic nature-nurture question, and TEDS results suggest that, especially in the area of learning abilities and disabilities, genes are generalists and environments are specialists. That is, genes largely contribute to similarity in performance within and between learning abilities and disabilities and across age, whereas the environment contributes to differences in performance. Quantitative genetic findings such as these chart the course for molecular genetic research. The TEDS dataset is proving valuable in genome-wide association research that tries to identify some of the many genes responsible for the ubiquitous heritability of behavior.

\section{Research Aims}

The first aim of the Twins' Early Development Study (TEDS) is to investigate the genetic and environmental origins of the most common behavioral problems in childhood within the context of normal variation. The second aim is to go beyond these rudimentary nature-nurture questions, to address the relationship between abilities and disabilities, conduct multivariate analyses of covariance within and between domains, and use longitudinal analyses to explore stability and change. The third aim is to use the large-scale, multivariate and longitudinal TEDS dataset for molecular genetic analyses that conduct genome-wide association scans to identify quantitative trait loci (QTLs) of small effect size. Early identification and remediation of common developmental disorders are critical to alleviating the long-term human suffering they cause, and understanding the genetic and environmental etiology of their developmental trajectories is a necessary part of achieving these goals.

In this article we briefly describe the procedural aspects of TEDS, as well as some of our quantitative genetic and molecular genetic findings.

\section{Initial Recruitment}

In 1994, with funding provided by TEDS, the Office of Population Census and Surveys (now the Office for National Statistics, ONS) contacted all traceable mothers of live-born twins in England and Wales in 1994, 1995 and 1996. These families form the sample frame for TEDS and details of their recruitment have been described in detail previously in this journal (Trouton et al., 2002). Since their initial enrolment TEDS participants have been contacted regularly; during assessment contacts, they are sent a small 'thank you' gift for each of the twins, as well as various participation incentives such as a yearly

Received 23 January, 2006; accepted 12 October, 2006.

Address for correspondence: Bonamy Oliver, Box P083, Social, Genetic and Developmental Psychiatry Centre, Institute of Psychiatry, King's College London, De Crespigny Park, London SE5 8AF, UK. E-mail: b.oliver@iop.kcl.ac.uk

Twin Research and Human Genetics Volume 10 Number 1 pp. 96-105 
Table 1

TEDS Samples and their Representativeness at Assessment Contacts

\begin{tabular}{|c|c|c|c|c|c|c|}
\hline & $\begin{array}{l}\text { Returned data } \\
\text { (N families) }\end{array}$ & $\%$ of contacted & $\%$ white* & $\%$ A-levels or higher & $\%$ mother employed ${ }^{*}$ & $\%$ father employed ${ }^{*}$ \\
\hline 1st contact & 13,732 & $84.2 \%$ & $91.7 \%$ & $35.5 \%$ & $43.1 \%$ & $91.7 \%$ \\
\hline 2-year booklet & 7009 & $65.8 \%$ & $93.3 \%$ & $36.4 \%$ & $41.2 \%$ & $92.2 \%$ \\
\hline 3-year booklet & 6126 & $65.5 \%$ & $93.3 \%$ & $37.9 \%$ & $43.4 \%$ & $92.8 \%$ \\
\hline 4-year booklet & 8222 & $65.6 \%$ & $93.3 \%$ & $40.4 \%$ & $44.5 \%$ & $93.1 \%$ \\
\hline 7-year study & 8209 & $56.3 \%$ & $93.5 \%$ & $40.4 \%$ & $46.4 \%$ & $93.0 \%$ \\
\hline 9-year study & 3894 & $51.7 \%$ & $93.7 \%$ & $39.1 \%$ & $46.1 \%$ & $93.1 \%$ \\
\hline 10-year study & 3997 & $63.6 \%$ & $93.8 \%$ & $39.9 \%$ & $46.5 \%$ & $93.2 \%$ \\
\hline
\end{tabular}

Note: ${ }^{*}$ The equivalent UK population percentages are $93 \%$ for $\%$ white, $32 \%$ for $\%$ A-levels or higher, $49 \%$ for $\%$ mother employed, and $89 \%$ for $\%$ father employed (Walker et al., 2001 ).

newsletter and handwritten birthday cards. At each assessment contact, informed consent is obtained. In order to maintain the sample as far as possible through the years, TEDS families are not invited to participate in all study stages; in particular, due to budget restraints, the 1996 birth cohort were excluded from several stages of data collection. In addition, at each assessment, invited families are given an option to withdraw from TEDS or not participate in that stage of the study. For this reason, full attrition analyses are not appropriate. However, Table 1 gives an indication of response rates and the representativeness of the sample.

\section{Measures}

Although TEDS data cover a considerable range of diverse abilities and behaviors, certain measures are central and are used in the majority of TEDS papers. These measures are intended to capture variation throughout the range of the normal distribution and to assess various behavioral traits, especially cognitive, language and behavior problems. These are described briefly in this section. As well as these core measures, TEDS has information on home and school environments, parenting, maternal depression, life events and other factors of child and adolescent life. Although not described here in the interests of space, details are available on request.

\section{Parental Measures by Post at 2, 3 and 4 Years}

When the twins were 12 to 18 months old, background information about the family was collected, including questions designed for the study about family structure, parental education and employment, perinatal experience including prenatal experiences (e.g., diet, blood pressure problems, alcohol consumption, smoking habits), and postnatal experiences (time in special care, time in hospital, respiratory problems), family health questions, and a physical similarity questionnaire used to help determine zygosity prior to the widespread use of DNA markers (Price et al., 2000).

Near their 2nd, 3rd and 4th birthdays, TEDS twins were assessed using parent-administered measures of verbal and nonverbal ability and behavior problems. For verbal ability, we used the UK short form version of the MacArthur Communicative Development Inventories (MCDI:UKSF; Dale et al., 1998), which assesses vocabulary, grammar and semantic/pragmatic ability. An age-appropriate version of the Parent Report of Children's Abilities (PARCA) developed for TEDS was used to assess nonverbal ability (see below). Behavior problems were assessed using parental ratings on standard measures including the Revised Rutter Parent Scale for Preschool children (RRPSPC; Hogg et al., 1997) and the Strengths and Difficulties Questionnaire (SDQ; Goodman, 1997).

\section{PARCA}

The PARCA is a nonverbal cognitive parental assessment originally designed for TEDS families (Oliver et al., 2002; Saudino et al., 1998) and now also used elsewhere (e.g., Johnson et al., 2004). Versions of the PARCA were developed for 2-, 3- and 4-year-olds. At each age, a PARCA total score is derived from two components: a questionnaire (Parent-Report [PR]) and a battery of cognitive tasks (Parent-Administered, [PA]). Both components include items modified from existing questionnaires and standard tests, as well as novel items written specifically for the PARCA. At each age the PARCA has a total administration time of around 1 hour. Items are selected on the basis of potential enjoyment for parent and child as well as developmental importance. All instructions aim to be as simple and explicit as possible for ease of administration.

PARCA: Validity. Although not a standard measure of nonverbal ability - because no such parental measures existed at the time - the validity of the PARCA has been demonstrated. For example, 107 2-year-olds (43 twin pairs and 7 triplets) were administered the 2year PARCA by their parents, and, 2 weeks later, the Bayley Scales of Infant Development-II (BSID-II; Bayley, 1993) by independent testers. A correlation of .55 was obtained between the PARCA total score and the Mental Development Index, rising to .66 when vocabulary and grammar scores from the MCDI:UKSF were also included (Saudino et al., 1998). Similarly, for the 3-year PARCA (PARCA3), 
the cognitive abilities of 85 children were assessed by their parents using the PARCA3 and then by independent testers on the McCarthy Scales of Children's Abilities (MSCA; McCarthy, 1972). The PARCA3 total score correlated .54 with a MSCA nonverbal composite (Oliver et al., 2002). For the 4-year old PARCA (PARCA4), examination of the in-home sample (see below) revealed that the correlations between general factors from the parent- and testeradministered batteries were .65 and .70 for first-born and second-born twins, respectively (Price, 2002). These validity data also provide minimal estimates of test-retest reliability because the standard cognitive tests were administered 2 weeks after the PARCA. The year-to-year stability of these measures was demonstrated in longitudinal analyses mentioned below (Spinath et al., 2003).

\section{In-Home Testing at 4 Years}

From the main TEDS sample a subsample of 834 pairs of twins was selected from the parent data completed at 4 years to be assessed at home on a battery of standard tests of language and nonlanguage ability. The in-home test battery consisted of various standardized measures chosen to cover several aspects of nonverbal cognitive ability and language. The MSCA (McCarthy, 1972) were administered in their entirety. In addition, the following tests were given: Bus Story and Action Pictures tasks from the Renfrew Language Scales (Renfrew, 1997a, 1997b), Phonological Awareness task (Bird et al., 1995), Goldman-Fristoe Test of Articulation (Goldman \& Fristoe, 1986), Children's Test of Nonword Repetition (Gathercole et al., 1994), British Ability Scales (BAS; Elliott et al., 1996).

\section{Telephone-Administered Assessment at 7 Years}

Although in-home testing allows conventional tests to be given by testers rather than parents, by 7 years some such measures can be administered by telephone. Two verbal tests (Similarities and Vocabulary) and two nonverbal tests (Picture Completion and Conceptual Grouping) were modified for telephone administration from the Wechsler Intelligence Scale for Children-III (WISC-III-PI ; Wechsler, 1992) and the MSCA (McCarthy, 1972). The measures retain as much of the original administration as possible, and all stimuli are essentially the same. Both instructions and stimuli were altered slightly to allow telephone administration; materials for testing were sent to parents prior to the telephone interview.

In order to investigate the strong relationship between verbal and nonverbal abilities and reading, the telephone test also included the Test of Word Reading Efficiency (TWRE; Torgesen et al., 1999). The TWRE has two subtests that distinguish whole word recognition skills from phonological decoding of words: Sight Word Efficiency, which assesses the number of real printed words that can be accurately read aloud within 45 seconds, and Phonetic Decoding
Efficiency, which measures the number of pronounceable printed non-words that can be accurately verbalized within 45 seconds.

Telephone-administered 7-year measures: Validity. Fifty-two children recruited as part of a larger volunteer family registry at Wesleyan University, United States, participated in a validation study for the telephone-administered measure (Petrill et al., 2002). These children were assessed using the telephone battery and then tested at home using the StanfordBinet Intelligence Scale (SB; Thorndike et al., 1986). A general cognitive ability composite from the telephone-administered battery and the SB correlated .62.

\section{Child Assessment at 9 Years}

Although telephone testing at 7 years worked well, its expense led us to use postal measures administered under the supervision of parents to assess the twins at 9 years. Again, the cognitive battery included two verbal tests (WISC-III-PI Vocabulary Multiple Choice and Information Multiple Choice) and two nonverbal tests (CAT3 Figure Classification and CAT3 Figure Analogies; Lohman et al., 2003).

\section{Teacher Assessments at 7, 9, 10, 12 and 14 Years}

At each contact teachers of TEDS twins are sent a questionnaire, along with a covering letter with the history and background of the study, and with confirmation of parental consent. Children in full-time UK education are assessed by their teachers throughout their school years through criteria and tests that are part of the UK National Curriculum (NC), developed by the Qualifications and Curriculum Authority (QCA; http://www.qca.org.uk) and the National Foundation for Educational Research (NFER; http://www.nfer.ac.uk/index.cfm). The QCA provides teachers with guidelines for assessment that cover diverse aspects of various domains, including English, Mathematics and Science. Along with the NC Direct Test score, the NC Teacher Assessment ultimately determines the final score submitted to the QCA to indicate the child's academic achievement at the end of the school year. The NC Teacher Assessments are obtained at each assessment. Just as for parent report, there is growing evidence for the validity of teacher assessments. In TEDS, for example, achievement in TEDS at 7 years has been found to correlate .58 with a general factor of the aforementioned telephoneadministered tests of verbal and nonverbal cognitive abilities (Spinath et al., 2003).

\section{Web-Based Assessment}

In 2002 it became clear that the Internet would provide the opportunity for web-based testing as the majority of UK families had access to the Internet. Few reasonable commercial testing possibilities were available at that time and thus we devoted substantial resources to develop and pilot web-based assessments suitable for the twins as they turned 10 years old. A 
major advantage of computer-based testing is that it facilitates adaptive branching which makes it possible to use hundreds of items to test the full range of ability but a child has only to complete a relatively small number of items to establish their performance level. TEDS measures are streamed with oral voiceovers to minimize reading load as far as possible. The test batteries are self-paced and can be completed over a period of several weeks. Tests are interspersed with games, which help to keep the children motivated. Informed consent is obtained, and a test administrator is assigned to telephone the family, sort out any problems, and generally assist and encourage the family.

\section{Web-Based Assessment at 10 Years}

At 10 years, the battery consists of web-based versions of reading, mathematics, and verbal and nonverbal cognitive tests. We adapted Peabody Individual Achievement Test - Revised (PIAT-R: Markwardt, 1989), Reading Comprehension and five subtests from the nferNELSON Maths 5-14 Series (2001): understanding number, nonnumerical processes, computation and knowledge, mathematical interpretation, and mathematical application. The two verbal tests were WISC-III-PI multiple-choice Vocabulary and Information, and the two nonverbal tests were WISCIII-UK Picture Completion and Raven's Standard Progressive Matrices (Raven et al., 1996).

Web-administered at 10 years: Validity. A composite of the five web-based mathematics tests correlated .58 with a teacher-assessed mathematics composite based on UK NC criteria. The cognitive composite yielded similar evidence for reliability and validity: The ' $\mathrm{g}$ ' composite correlated .60 with a battery of cognitive tests administered to a subsample of TEDS children at 9 years.

\section{Web-Based Assessment at 12 and 14 Years}

Starting in 2006, TEDS twins are assessed at 12 and 14 years on web-based tests that include similar measures of mathematics (three subtests only) and verbal and nonverbal cognitive ability. As described below, a new battery of language measures was developed and additional measures of reading included. We also include two measures of spatial ability (Hidden Patterns: nferNELSON Spatial Reasoning Series 8-11; Jigsaws: nferNELSON Spatial Reasoning Series 8-9, 12-14). Finally, on an experimental basis we include a measure of social cognition (The Eyes Test: BaronCohen et al., 2001). In addition to these cognitive measures, we assess, by postal questionnaire, pubertal development (Petersen et al., 1988) and behavior problems, including measures of general behavior problems (SDQ; Goodman, 1997), autistic spectrum symptoms (CAST; Scott et al., 2002), and hyperactivity (Conners; Conners, 2001). We also include measures of the environment similar to those used previously in TEDS such as parental discipline (Deater-Deckard et al., 1998), parental warmth
(Deater-Deckard, 2000), and family chaos (Matheny et al., 1995), as well as victimization (Mynard \& Joseph, 2000).

Language. The most novel aspect of our testing program at 12 and 14 years involves the development of a web-based language battery suitable for adolescents. Our goal was to assess syntax (Listening Grammar: Test of Adolescent and Adult Language; Hammill et al., 1994), semantics (Figurative Language: Test of Language Competence [Expanded Edition]; TLC; Wiig \& Secord, 1989), and pragmatics (Making Inferences: TLC), and to measure these linguistic features along a dimension of metalinguistic ability, which becomes increasingly important in adolescence.

Reading. The following three tests were adapted for web administration: PIAT-R Reading Comprehension, GOAL Formative Assessment in Key Stage 3 Literacy (GOAL Plc., 2002), and Woodcock-Johnson III Tests of Achievement, Reading Fluency (Woodcock et al., 2001). In addition, the TWRE was administered over the telephone, as at 7 years (see above).

\section{Research Findings}

Since 2000, more than 80 empirical papers using the TEDS dataset are in press or published. This extensive body of TEDS research precludes a comprehensive summary of research findings in this brief paper. However, following are some examples of quantitative genetic and molecular genetic results and references from TEDS.

\section{Quantitative Genetic Findings Univariate Results}

In early childhood (2, 3 and 4 years) TEDS has confirmed modest genetic influence and substantial shared environmental influence for verbal, nonverbal and general cognitive abilities and disabilities (Spinath et al., 2003), as well as in the first large-scale analysis of mild mental impairment (Spinath et al., 2004). TEDS has also investigated some less well-studied domains in early childhood, most notably language (e.g., Colledge et al., 2002; Kovas et al., 2005; Viding et al., 2004). In the middle childhood years, TEDS has focused on learning abilities and disabilities, finding high heritability and moderate shared environmental influence in the first studies of early reading (Harlaar, Spinath, et al., 2005) and mathematics (Oliver et al., 2004); we are currently investigating writing and science. In most of these analyses, we compared the etiology of the extremes to those of the normal distribution. These results generally support the hypothesis that common disorders such as learning disabilities are the quantitative extreme of the same genetic and environmental factors that contribute to normal variation such as learning abilities, and thus support the QTL approach to molecular genetics which assumes that many genes of small effect are responsible for both disabilities and abilities (discussed below). 
In relation to behavior problems, we have confirmed other research in showing substantial genetic influence and negligible shared environmental influence for diverse behavior problems (Saudino et al., 2005). A more novel finding concerns antisocial behavior in middle childhood. Similar to other studies, antisocial behavior shows only modest heritability and moderate shared environmental influence; however, the callous-unemotional personality component of antisocial behavior shows very high heritability and little shared environmental influence (Viding et al., 2005). In addition, we have analyzed aspects of adjustment that have not previously been studied such as gender role development (Knafo et al., 2005; Iervolino et al., 2005) and prosocial behavior. For prosocial behavior - assessed by parents at 3, 4 and 7 years, and by teachers at 7 - genetic effects increased and shared environmental effects decreased over time (Knafo \& Plomin, in press).

\section{Multivariate Results}

In the cognitive domains of language and learning abilities and disabilities, the most striking finding is substantial genetic covariance within and between domains. For example, within language, we found that lexical and grammatical development shows genetic overlap (Dale et al., 2000; Dionne et al., 2003); considerable genetic overlap was also found across different linguistic domains at 4.5 years (Hayiou-Thomas et al., in press). Genetic correlations are also substantial across domains, with genetic correlations of about .70 between language and nonverbal factors for normal variation (Colledge et al., 2002) and at the low extreme (Viding et al., 2003), and between general cognitive ability and reading (Harlaar, Hayiou-Thomas et al. 2005), and mathematics (Kovas et al., 2005).

Research of this kind has led to our Generalist Genes Hypothesis of learning abilities and disabilities, predicting that many of the genes associated with one cognitive domain such as reading will also be associated with others such as mathematics and language (Plomin \& Kovas, 2005). In contrast, our work suggests that environmental influences are more domain specific. This theory has far-reaching implications in relation to neuroscience because it goes against the view of modularity of brain function (Kovas \& Plomin, 2006). Molecular genetic research will provide definitive tests of the theory.

For behavior problems, an exciting and unexpected result has emerged from multivariate genetic analysis of behaviors characteristic of autistic spectrum disorder (ASD). Diagnoses of ASD require deficits in both social and nonsocial behaviors but our multivariate genetic results show marked genetic heterogeneity (genetic correlations of only .20) between the social and nonsocial components of ASD as assessed by teachers and by parents at 7 years (Ronald et al., 2005). A follow-up study found similar results at 8 years (Ronald et al., in press). These results suggest that different genes affect the social and nonsocial components of ASD. We are using these findings to guide our molecular genetic research on ASD, which aims to identify QTLs separately for these two components.

Incorporating measures of the environment in multivariate genetic analyses facilitates analyses of the developmental interface between nature and nurture (Rutter, 2006). In TEDS, significant genetic mediation has been found, for example, between school and classroom environment (Walker \& Plomin, in press), and between parenting and prosocial behavior (Knafo \& Plomin, 2005). Environmental measures also make possible analyses of nonshared environment using the powerful test of discordant monozygotic (MZ) twins (Asbury et al., 2006, in press) and analyses of genotype-environment interaction (Asbury et al., 2005).

\section{Longitudinal Results}

The longitudinal nature of TEDS allows the exploration of stability and change through childhood and adolescence. For example, TEDS data show some spontaneous resolution of delayed language in preschoolers (Dale et al., 2003), with data suggesting that transient and persistent early language delays may be different in their etiological origins (Bishop et al., 2003). Furthermore, cross-lagged longitudinal genetic models of lexical and grammatical abilities in 2- and 3 -year olds suggest that genetic influences on vocabulary contribute to grammar and genetic influences on grammar contribute to vocabulary, suggesting both lexical and syntactical bootstrapping in operation in the early years, despite the fact that lexical development is usually assumed to drive the development of grammar (Dionne et al., 2003).

Considerable genetic stability and environmental change has been found in TEDS for general cognitive ability (Spinath et al., 2003), low verbal and nonverbal performance (Price et al., 2004), and hyperactivity (Kuntsi et al.; 2005, Price et al., 2005). Moreover, TEDS findings suggest that multivariate phenotypic and genetic connections can be seen developmentally. For example, language impairment at 4.5 years is predicted nearly as well by earlier nonverbal ability as by language with predictions mediated primarily by genetic and shared environmental factors (Oliver et al., 2004). Reading at 7 years is predicted as much by nonverbal ability as by language at 4.5 years with genetic and shared environmental influences contributing for the most part to the associations (Hayiou-Thomas et al., 2006). Furthermore, both literacy experience and preliteracy knowledge at age 4 predict reading and writing skills at age 7 , with these predictions also largely mediated by genetic and shared environmental factors (Oliver et al., 2004). Other longitudinal analyses in TEDS have shown nonshared environmental influences to be important longitudinally. For example, birthweight-discordance and differences in early parenting style are related to 
MZ twin differences in behavior problems and academic achievement at age 7 (Asbury et al., 2006).

\section{Molecular Genetic Findings}

Twin studies such as TEDS are valuable for molecular genetic research for three reasons. First, large samples are needed to address the demand for power that comes from recognizing that genetic influence on common disorders and complex dimensions are likely to involve many more QTLs of much smaller effect sizes than previously considered. Second, large twin studies are cost-effective because they often offer rich multivariate and longitudinal datasets for analysis once DNA is obtained. Third, for developmental disorders, twins offer the perfect age-matched within-family comparison to protect against spurious associations due to population stratification. In addition, MZ twins offer a unique opportunity to study epigenetic differences such as Xinactivation (Loat et al., 2004).

During the past few years there have been rapid developments towards genome-wide association scans using single-nucleotide polymorphism (SNP) microarrays that can genotype hundreds of thousands of SNPs distributed throughout the genome (Plomin, 2005). Microarrays are expensive and typically can be used only once, which means that it would be very expensive to conduct a microarray study using the very large samples needed to detect QTLs of small effect size. However, in TEDS we have developed a novel strategy that uses SNP microarrays to genotype DNA pooled across individuals in extreme groups such as cases versus controls or low versus high groups on a quantitative trait. In other words, instead of using thousands of microarrays to genotype large samples, a single microarray can be used to estimate average SNP allelic frequencies for a group's pooled DNA, averaging individuals biologically rather than statistically. We have applied this approach - which we call SNP Microarrays and Pooling (SNP-MaP; Butcher et al., 2004; Meaburn et al., 2005, 2006) - to identify SNPs associated with learning disabilities in TEDS. These genome-wide association studies have confirmed the expectation that QTL effects are very small: the largest effect size of SNPs detected to date is $.4 \%$ for mild mental impairment (Butcher et al., 2005) and for reading in a study nearing completion. Although each SNP has a small effect, we have shown that SNPs can be aggregated into a genetic risk index - like aggregating items on a composite scale. We have called this genotypic composite a SNP set which we have used in top-down behavioral genomic analyses of the longitudinal, multivariate TEDS dataset (Harlaar, Butcher, et al., 2005). For example, a SNP set that we identified for mild mental impairment at 7 years (Butcher et al., 2005) showed longitudinal associations with general cognitive ability as early as 2 years, multivariate associations with reading ability, and gene-environment interactions and correlations with environmental measures (Harlaar, Butcher, et al., 2005).

\section{Future Plans}

Our quantitative and molecular genetic analyses will be enriched as we follow the TEDS twins into adolescence, especially with the detailed assessments of learning abilities and disabilities made possible by web-based testing.

Far from quantitative genetics winding down in this age of molecular genetics, we believe that quantitative genetic analyses - especially analyses of multivariate and longitudinal issues, links between the normal and the abnormal, and genotype environment interplay - are increasingly important in order to chart the course for molecular genetic analyses.

Our first SNP-MaP study used the 10,000-SNP microarray available in 2004 for our study of mild mental impairment (Butcher et al., 2005) and the 100,000-SNP microarray available in 2005 for our study of reading disability (Meaburn et al., 2005). Our ongoing molecular genetic research applies our SNP-MaP approach to new microarrays that genotype 500,000 SNPs and thus approach a true genome-wide association analysis. As well as the study of QTLs for two components of ASD discussed earlier, we are currently conducting a SNP-MaP study using the $500,000-S N P$ microarray in a design that aims to identify QTLs for genotype-environment interaction and correlation for general cognitive ability (Plomin \& Palfrey-Davis, in press).

We are most excited about an unexpected finding of potentially great importance that is emerging from our genome-wide association studies: Often SNPs associated with complex traits do not reside in or even near known genes, the $2 \%$ of the genome that is transcribed into RNA and then translated into amino acid sequences. Although SNP associations in such intergenic regions would previously have been dismissed as nonsensical, there is great interest in their possible functionality, especially in relation to QTL associations with common disorders and complex traits. Our genome-wide association findings mesh with recent evidence that much of the other $98 \%$ of DNA in the genome is transcribed into RNA but not translated, including DNA far away from any coding DNA regions. Such intergenic noncoding RNA is now known to regulate the expression of genes and gene products throughout the genome (Mattick \& Makunin, 2006). Given this possibility, it is important to move towards genome-wide association scans rather than focusing on a small number of candidate genes because QTLs may not reside in coding regions.

Over the last decade, as TEDS twins have developed from infancy through to late childhood, TEDS researchers have made also made considerable progress. Findings from TEDS, just some of which are touched on in this review, have contributed to univariate, multivariate and longitudinal research from both quantitative and molecular genetic perspectives. In that time, exciting new developments in understanding genes, environment and their interplay - through TEDS research and elsewhere 
- have raised brand new research questions. We look forward to exploring some of these questions as TEDS twins progress into adolescence.

\section{Acknowledgments}

TEDS was funded originally in 1995 and continuously subsequently by a program grant from the U.K. Medical Research Council (G9424799, now G050079). Funding has also been received to develop additional areas of research from the U.S. National Institute of Child Health and Human Development (HD) for a quantitative genetic study of school environments (HD44454) and of mathematics (HD46167), and for molecular genetic research on reading (HD49861); the Wellcome Trust is also supporting our molecular genetic research on cognitive abilities (GR75492). Our enormous thanks to TEDS families for their continuing support.

\section{References}

Asbury, K., Dunn, J., \& Plomin, R. (in press). The use of discordant $\mathrm{MZ}$ twins to generate hypotheses about nonshared environmental influence on anxiety in middle childhood. Social Development.

Asbury, K., Dunn, J. F., \& Plomin, R. (2006). Birthweight-discordance and differences in early parenting relate to monozygotic twin differences in behaviour problems and academic achievement at age 7. Developmental Science, 9, F22-F31.

Asbury, K., Wachs, T., \& Plomin, R. (2005). Environmental moderators of genetic influence on verbal and nonverbal abilities in early childhood. Intelligence, 33, 643-661.

Baron-Cohen, S., Wheelwright, S., Hill, J., Raste, Y., \& Plumb, I. (2001). The 'reading the mind in the eyes' test revised version: A study with normal adults, and adults with Asperger syndrome or high-functioning autism. Journal of Child Psychology and Psychiatry, 42, 241-251.

Bayley, N. (1993). Bayley Scales of Infant Development. New York, NY: The Psychological Corporation.

Bird, J., Bishop, D. V. M., \&. Freeman, N. H. (1995). Phonological awareness and literacy development in children with expressive phonological impairments. Journal of Speech and Hearing Research, 38, 446-462.

Bishop, D. V., Price, T. S., Dale, P. S., \& Plomin, R. (2003). Outcomes of early language delay: II. Etiology of transient and persistent language difficulties. Journal of Speech and Hearing Research, 46, 561-575.

Butcher L. M., Meaburn E., Knight J., Sham P. C., Schalkwyk L. C., Craig I. W., \& Plomin, R. (2005). SNPs, microarrays and pooled DNA: Identification of four loci associated with mild mental impairment in a sample of 6000 children. Human Molecular Genetics, 14, 1315-1325.
Butcher, L. M., Meaburn, E., Liu, L., Fernandes, C., Hill, L., Al-Chalabi, A., Plomin, R., Schalkwyk, L., \& Craig, I. W. (2004). Genotyping pooled DNA on microarrays: A systematic genome screen of thousands of SNPs in large samples to detect QTLs for complex traits. Behavior Genetics, 34, 549-555.

Colledge, E., Bishop, D. V. M., Koeppen Schomerus, G., Price, T. S., Happé, F. G. E., Eley, T. C., Dale, P. S., \& Plomin, R. (2002). The structure of language abilities at 4 years: A twin study. Developmental Psychology, $38,749-757$.

Conners, C. K. (2001). Conners' Rating Scale-Revised. Tonawanda, New York: Multi Health Systems Inc.

Dale, P. S., Price, T. S., Bishop, D. V., \& Plomin, R. (2003). Outcomes of early language delay: I. Predicting persistent and transient language difficulties at 3 and 4 years. Journal of Speech, Language and Hearing Research, 46, 544-560.

Dale, P. S., Dionne, G., Eley, T. C., \& Plomin, R. (2000). Lexical and grammatical development: A behavioural genetic perspective. Journal of Child Language, 27, 619-642.

Dale, P. S., Simonoff, E., Bishop, D. V. M., Eley, T. C., Oliver, B., Price, T. S., Purcell, S., Stevenson, J., \& Plomin, R. (1998). Genetic influence on language delay in two-year-old children. Nature Neuroscience, 1, 324-328.

Deater-Deckard, K. (2000). Parenting and child behavioural adjustment in early childhood: A quantitative genetic approach to studying family processes. Child Development, 71, 468-484.

Deater-Deckard, K., Dodge, K. A., Bates, J. E., \& Pettit, G. S. (1998). Multiple risk factors in the development of externalising behavior problems: Group and individual differences. Development and Psychopathology, 10, 469-493.

Dionne, G., Dale, P. S., Boivin, M., \& Plomin, R. (2003). Genetic evidence for bidirectional effects of early lexical and grammatical development. Child Development, 74, 394-412.

Elliott, C. D., Smith P., \& McCulloch K. (1996). Verbal Comprehension Scale from British Ability Scales (2nd ed.). Windsor, Berks: nferNELSON.

Gathercole, S. E., Willis, C., Baddeley, A. D., \& Emslie, H. (1994). The children's test of nonword repetition: A test of phonological working memory. Memory, 2, 103-127.

Goldman, R., \& Fristoe, M. (1986). Goldman-Fristoe Test of Articulation. Circle Pines, MN: American Guidance Service.

GOAL Plc. (2002). Goal formative assessment in literacy: Key stage 3. London, UK: Hodder \& Stoughton.

Goodman, R. (1997). The Strengths and Difficulties Questionnaire: A research note. Journal of Child Psychology and Psychiatry and Allied Disciplines, 38, 581-586. 
Hammill, D. D., Brown, V. A., Larsen, S. C., \& Wiederholt, J. L. (1994). Test of Adolescent and Adult Language (Intermediate, 3rd ed.). Austin: PRO-ED.

Harlaar, N., Butcher, L. M., Meaburn, E., Sham, P., Craig, I. W., \& Plomin, R. (2005). A behavioural genomic analysis of DNA markers associated with general cognitive ability in 7-year-olds. Journal of Child Psychology and Psychiatry, 46, 1097-1107.

Harlaar, N., Hayiou-Thomas, M. E., \& Plomin, R. (2005). Reading and general cognitive ability: A multivariate analysis of 7-year-old twins. Scientific Studies of Reading, 9, 197-218.

Harlaar, N., Spinath, F. M., Dale, P. S., \& Plomin, R. (2005). Genetic influences on early word recognition abilities and disabilities: A study of 7-year-old twins. Journal of Child Psychology and Psychiatry, 46, 373-384.

Hayiou-Thomas, M. E., Harlaar, N., Dale, P., \& Plomin, R. (2006). Genetic and environmental mediation of the prediction from preschool language and nonverbal ability to 7-year reading. Journal of Research in Reading, 29, 50-74.

Hayiou-Thomas, M. E., Kovas, K., Harlaar, N., Bishop, D. V. M., Dale, P. S., \& Plomin, R. (in press). Common aetiology for diverse language skills in 4year-old twins. Journal of Child Language.

Hogg, C., Rutter, M., \& Richman, N. (1997). Emotional and Behavioural Problems in Children. In I. Insclare (Ed.), Child psychology portfolio. Windsor: nferNELSON.

Iervolino, A. C., Hines, M., Golombok, S. E., Rust, J., \& Plomin, R. (2005). Genetic and environmental influences on sex-typed behavior during the preschool years. Child Development, 76, 826-840.

Johnson, S., Marlow, N., Wolke, D., Davidson, L., Marston, L., O'Hare, A., Peacock, J., \& Schulte, J. (2004). Validation of a parent report measure of cognitive development in very preterm infants. Developmental Medicine and Child Neurology, 46, 389-397.

Knafo, A., Iervolino, A. C., \& Plomin, R. (2005). Masculine girls and feminine boys: Genetic and environmental contributions to atypical gender development in early childhood. Journal of Personality and Social Psychology, 88, 400-412.

Knafo, A., \& Plomin, R. (2005). Parental discipline and affection, and children's prosocial behavior: Genetic and environmental links. Journal of Personality and Social Psychology, 90, 147-164.

Knafo, A., \& Plomin, R. (in press). Prosocial behavior from early to middle childhood: Genetic and environmental influence on stability and change. Journal of Personality and Social Psychology.

Kovas, Y., Harlaar, N., Petrill, S. A., \& Plomin, R. (2005). 'Generalist genes' and mathematics in 7-year-old twins. Intelligence, 33, 473-489.

Kovas, Y., Hayiou-Thomas, M. E., Oliver, B., Dale, P. S., Bishop, D. V. M., \& Plomin, R. (2005). Genetic influences in different aspects of language development: The etiology of language skills in 4.5-year-old twins. Child Development, 76, 632-651.

Kovas, Y., \& Plomin, R. (2006). Generalist genes: implications for the cognitive sciences. Trends in Cognitive Science, 10, 198-203.

Kuntsi, J., Rijsdijk F., Ronald A., Asherson P., \& Plomin, R. (2005). Genetic influences on the stability of attention-deficit/hyperactivity disorder symptoms from early to middle childhood. Biological Psychiatry, 57, 647-654.

Loat, C., Asbury, K., Galsworthy, M. J., Plomin, R., \& Craig, I. (2004). X inactivation as a source of behavioural differences in monozygotic female twins. Twin Research, 7, 54-61.

Lohman, D. F., Hagen, E. P., \& Thorndike, R. L. (2003). Cognitive Abilities Test: Third Edition (CAT3). Windsor: nferNELSON.

Markwardt, F. C., Jr. (1989). Peabody Individual Achievement Test - Revised. Circle Pines, MN: American Guidance Service.

Mathey, A. P., Wachs, T. D., Ludwig, J. L., \& Philipps, K. (1995). Bringing order out of chaos: Psychometric characteristics of the Confusion, Hubbub and Order Scale. Journal of Applied Developmental Psychology, 16, 429-444.

Mattick, J. S., \& Makunin, I. V. (2006). Non-coding RNA. Human Molecular Genetics, 15, R17-29.

McCarthy, D. A. (1972). McCarthy Scales of Children's Abilities. San Antonio, TX: The Psychological Corporation.

Meaburn, E., Butcher, L. M., Liu, L., Fernandes, C., Hansen, V., Al-Chalabi, A., Plomin, R., Craig, I., \& Schalkwyk, L. (2005). Genotyping DNA pools on microarrays: Tackling the QTL problem of large samples and large numbers of SNPs. BioMed Central Genomics, 6, 52-60.

Meaburn, E., Butcher, L., Schalkwyk, L., \& Plomin, R. (2006). Genotyping pooled DNA using 100K SNP microarrays: A step towards genomewide association scans. Nucleic Acids Research, 34, e27.

Mynard, H., \& Joseph, S. (2000). Development of the Multidimensional Peer-Victimization Scale. Aggressive Behavior, 26, 169-178.

Oliver, B., Dale, P. S., \& Plomin, R. (2004). Verbal and nonverbal predictors of early language problems: An analysis of twins in early childhood back to infancy. Journal of Child Language, 31, 609-631.

Oliver, B., Dale, P. S., Saudino, K. J., Petrill, S. A., Pike, A., \& Plomin, R. (2002). The validity of a parentbased assessment of cognitive abilities in 3-year olds. Early Child Development and Care, 172, 337-348.

Oliver, B., Harlaar, N., Hayiou-Thomas, M. E., Kovas, Y., Walker, S. O., Petrill, S. A., Spinath, F. M., Dale, P. S., \& Plomin, R. (2004). A twin study of teacherreported mathematics performance and low 
performance in 7-year-olds. Journal of Educational Psychology, 96, 504-517.

Petersen, A. C., Crockett, L., Richards, M., \& Boxer, A. (1988). A self-report measure of pubertal status: reliability, validity, and initial norms. Journal of Youth and Adolescence, 17, 117-133.

Petrill, S. A., Rempell, J., Oliver, B., \& Plomin, R. (2002). Testing cognitive abilities by telephone in a sample of 6-to 8-year olds. Intelligence, 30, 353-360.

Plomin, R. (2005). Finding genes in child psychology and psychiatry: When are we going to be there? Journal of Child Psychology and Psychiatry, 46, 1030-1038.

Plomin, R., \& Kovas, Y. (2005). Generalist Genes and Learning Disabilities. Psychological Bulletin, 131, 592-617.

Plomin, R., \& Palfrey-Davis, O. (in press). Gene-environment interactions and correlations in the development of cognitive abilities and disabilities. In J. MacCabe, O. O’Daly, R. M. Murray, P. McGuffin, \& P. Wright (Eds.), Beyond nature and nurture: Genes, environment and their interplay in psychiatry. London: Martin Dunitz.

Price, T. S. (2002). Genetic and environmental influences on verbal and nonverbal domains of cognitive ability and low cognitive ability: A study of 2-, 3-, and 4year-old twins. Ph.D Dissertation.

Price, T. S., Dale, P. S., \& Plomin, R. (2004). A longitudinal genetic analysis of low verbal and nonverbal cognitive abilities in early childhood. Twin Research, 7, 139-148.

Price, T. S., Freeman, B., Craig, I. W., Petrill, S. A., Ebersole, L., \& Plomin, R. (2000). Infant zygosity can be assigned by parental report questionnaire data. Twin Research, 3, 129-133.

Price, T. S., Simonoff, E., Asherson, P., Curran, S., Kuntsi, J., Waldman, I., \& Plomin, R. (2005). Continuity and change in preschool ADHD symptoms: longitudinal genetic analysis with contrast effects. Behavior Genetics, 35, 121-132.

Raven, J. C., Court, J. H., \& Raven, J. (1996). Manual for Raven's Progressive Matrices and Vocabulary Scales. Oxford: Oxford University Press.

Renfrew, C. E. (1997a). Action Picture Test. Bicester: Winslow Press Ltd.

Renfrew, C. E. (1997b). Bus Story Test: A test of narrative speech. Bicester: Winslow Press Ltd.

Ronald, A., Happé, F., Bolton, P., Butcher, L. M., Price, T. S., Wheelwright, S., Baron-Cohen, S., \& Plomin, R. (in press). Genetic heterogeneity between the three components of the autism spectrum: A twin study. Journal of the American Academy of Child and Adolescent Psychiatry.

Ronald A., Happé, F., \& Plomin, R. (2005). The genetic relationship between individual differences in social and nonsocial behaviors characteristic of autism. Developmental Science, 8, 444-458.
Rutter, M. (2006). Genes and behavior: Nature-nurture interplay explained. Oxford: Blackwell Publishing.

Saudino, K. J., Dale, P. S., Oliver, B., Petrill, S. A., Richardson, V., Rutter, M., Simonoff, E., Stevenson, J., \& Plomin, R. (1998). The validity of parent-based assessment of the cognitive abilities of 2-year-olds. British Journal of Developmental Psychology, 16, 349-363.

Saudino, K. J., Ronald, A., \& Plomin, R. (2005). The etiology of behavior problems in 7-year-old twins: Substantial genetic influence and negligible shared environmental influence for parent ratings and ratings by same and different teachers. Journal of Abnormal Child Psychology, 33, 113-130.

Scott, F. J., Baron-Cohen, S., Bolton, P., \& Brayne, C. (2002). The CAST (Childhood Asperger Syndrome Test): Preliminary development of a UK screen for mainstream primary-school-age children. Autism, 6, 9-31.

Spinath, F. M., Harlaar, N., Ronald, A., \& Plomin, R. (2004). Substantial Genetic Influence on Mild Mental Impairment in Early Childhood. American Journal on Mental Retardation, 109, 34-43.

Spinath, F. M., Ronald, A., Harlaar, N., Price, T. S., \& Plomin, R. (2003). Phenotypic g early in life: On the etiology of general cognitive ability in a large population sample of twin children aged 2-4 years. Intelligence, 31, 195-210.

Thorndike, R. L., Hagen, E. P., \& Sattler, J. M. (1986). Technical Manual for the Stanford-Binet Intelligence Scale (4th ed.). Chicago: Riverside.

Torgesen, J. K., Wagner, R. K., \& Rashotte, C. A. (1999). Test of Word Reading Efficiency (TOWRE). Austin, TX: Pro-Ed.

Trouton, A., Spinath, F. M., \& Plomin, R. (2002). Twins Early Development Study (TEDS): A multivariate, longitudinal genetic investigation of language, cognition and behavior problems in childhood. Twin Research, 5, 444-448.

Viding, E., Blair, R., James R., Moffitt, T. E., \& Plomin, R. (2005). Evidence for substantial genetic risk for psychopathy in 7-year-olds. Journal of Child Psychology and Psychiatry, 46, 592-597.

Viding, E., Price, T. S., Spinath, F. M., Bishop, D. V. M., Dale, P. S., \& Plomin, R. (2003). Genetic and environmental mediation of the relationship between language and nonverbal impairment in 4-year-old twins. Journal of Speech, Language, and Hearing Research, 46, 1271-1282.

Viding, E., Spinath, F. M., Price, T. S., Bishop, D. V. M., Dale, P. S., \& Plomin, R. (2004). Genetic and environmental influence on language impairment in 4-year-old same-sex and opposite-sex twins. Journal of Child Psychology and Psychiatry, 45, 315-325.

Walker, A., Maher, J., Coulthard, M., Goddard, E., \& Thomas, M. (2001). Living in Britain: Results from the 2000/2001 General Household Survey. London: TSO. 
Walker, S. O., \& Plomin, R. (in press). Nature, nurture, and perceptions of the classroom environment as they relate to teacher assessed academic achievement: A twin study of 9-year-olds. Educational Psychology.

Wechsler, D. (1992). Wechsler Intelligence Scale for Children - Third Edition UK (WISC-IIIUK) Manual. London: The Psychological Corporation.
Wiig, E., \& Secord, W. (1989). Test of Language Competence - Expanded Edition: Administration Manual Level 1 and Level 2. San Antonio, TX: Psychological Corporation.

Woodcock, R. W., McGrew, K. S., \& Mather, N. (2001). Woodcock-Johnson III Tests of Achievement. Itasca, IL: Riverside. 